\title{
Vacunas de ADN: inducción de la respuesta inmunitaria
}

\author{
Javier Mota-Sánchez, Dr. ${ }^{(1)}$
}

\begin{abstract}
Mota-Sánchez J.
Vacunas de ADN: inducción de la respuesta inmunitaria. Salud Publica Mex 2009;5I supl 3:S463-S469.
\end{abstract}

\section{Resumen}

La efectividad de las vacunas y la inmunización en la prevención de las enfermedades infecciosas es uno de los grandes avances de la medicina. En la actualidad, el acceso a la tecnología de punta en el área de la genómica y la proteómica ha hecho posible acelerar el desarrollo de nuevos modelos de vacunas con características mejoradas en aspectos fundamentales, como la inmunogenicidad y la seguridad. A casi dos décadas del primer informe, en el cual se demostró que un gen puede expresarse mediante la inyección directa de ADN desnudo, las vacunas de ADN han probado ser eficientes para inducir una respuesta inmunitaria protectora contra parásitos, virus y bacterias en diversos modelos animales. Esta revisión tiene por objetivo presentar un panorama general de las vacunas de ADN y los mecanismos mediante los cuales la inmunización con antígenos insertados en vectores de ADN (plásmidos) inducen una respuesta inmunitaria.

Palabras clave: vacunas;ADN; respuesta inmunitaria

\author{
Mota-Sánchez J. \\ DNA Vaccines: Induction of the immune response. \\ Salud Publica Mex 2009;5 I suppl 3:S463-S469.
}

\begin{abstract}
The effectiveness of vaccines and immunization in the prevention of infectious diseases is one of the greatest successes in medicine. In recent years, with access to cutting edge genomic and proteomic technology, it is possible to accelerate the development of new and improved vaccines with better immunogenicity and safety characteristics. Since the first report almost two decades ago, where it was demonstrated that gene expression is possible by directed injection of naked DNA, DNA vaccines have been proven to induce protective immune responses against parasites, virus and bacterium in diverse animal disease models. This review aims to present an overview about DNA vaccines and the mechanisms by which immune responses are induced after immunization with plasmid DNA-encoded antigens.
\end{abstract}

Key words: vaccines; DNA; immune response
U no de los acontecimientos más importantes en la historia de la medicina es la vacunación; el desarrollo e institución de esquemas regulares de inmunización han permitido controlar de manera exitosa muchas enfermedades e incluso erradicar la viruela en el ámbito mundial. ${ }^{1}$ La vacunación ha probado ser la medida más exitosa en términos de costo-beneficio, ${ }^{2}$ si bien las enfermedades infecciosas son aún una de las causas principales de muerte en el mundo. Se calcula que alrededor de $25 \%$ del total de muertes anuales en el mundo (alrededor de 15 millones) se debe a agentes infecciosos, ${ }^{3}$ no sólo por la aparición de nuevos patógenos, como el

(I) Centro de Investigación sobre Enfermedades Infecciosas, Instituto Nacional de Salud Pública. Cuernavaca, Morelos, México. 
virus Ebola, el virus de la inmunodeficiencia humana (VIH) o el coronavirus relacionado con el síndrome respiratorio agudo grave, sino también debido a la reaparición de microorganismos causantes de enfermedades con elevadas tasas de morbilidad y mortalidad, como la influenza, la fiebre del Nilo Occidental, la fiebre por dengue, el cólera o el paludismo.,4

Para estas y muchas otras enfermedades no existen fármacos o vacunas. Pese a ello, avances recientes en la ciencia básica y la medicina han permitido el desarrollo de vacunas con mejores características inmunogénicas y de seguridad. Las nuevas aproximaciones de la "vacunología reversa" (reverse vaccinology) ha revolucionado la investigación en el área de la patogenia de los microorganismos y el diseño de vacunas, ${ }^{5}$ por lo que no es difícil imaginar que en un futuro próximo estén disponibles vacunas eficaces y seguras para estas enfermedades.

Las primeras vacunas se produjeron de manera empírica, sin un conocimiento detallado de la naturaleza del agente causal y los efectos en los individuos inmunizados. Por ejemplo, las observaciones de que una infección leve de viruela protegía contra la enfermedad en exposiciones subsecuentes posibilitaron el uso de pus seca como una forma de inóculo aplicado en la piel, o en forma intranasal, para prevenir la enfermedad. Esto culminó en el año 1798 con la publicación del trabajo de Edward Jenner sobre la vacunación con el virus de la viruela, un acontecimiento reconocido como el nacimiento de la inmunología. ${ }^{6}$ Con posterioridad, el avance en el conocimiento de la microbiología, en especial la depuración de las técnicas de cultivo de tejidos, permitió el desarrollo sistemático de vacunas contra muchas enfermedades y, más aún, se han ideado esquemas de inmunización mediante vacunas polivalentes, como la vacuna triple contra la difteria-tétanos-tos ferina, conocida como DTP. ${ }^{7}$ Esto dio como resultado un menor requerimiento de inyecciones múltiples; con base en este razonamiento, en fecha reciente se demostró la eficacia e inmunogenicidad de una vacuna hexavalente que contiene además de DTP, hepatitis B, polio y Haemophilus influenzae tipo B. ${ }^{8}$ Sin embargo, y a pesar del aparente éxito de esta vacuna hexavalente, existe aún la preocupación acerca de su seguridad en su uso masivo. ${ }^{9}$

El conocimiento acumulado en el último siglo en disciplinas como la virología, la biología molecular y la propia inmunología ha permitido comprender mejor el éxito y los errores de las vacunas usadas en el pasado, así como también contar con nuevas herramientas y estrategias para el diseño y desarrollo de mejores inmunizaciones; ${ }^{6,10}$ las vacunas de ADN son un ejemplo de ello.

\section{Las primeras vacunas}

En la historia de la inmunología, las primeras inmunizaciones exitosas fueron las vacunas atenuadas, elaboradas en esencia con virus vivos atenuados mediante múltiples procesos en cultivos de tejidos; son ejemplos el virus de la viruela o el virus de la polio ya mencionados. Otro tipo de vacunas atenuadas se basó en la inactivación química o por calor. El éxito de las vacunas atenuadas se basa en su capacidad de inducir una respuesta inmunitaria tanto humoral como celular;, ${ }^{11}$ no obstante, en el caso de la inactivación química o por calor, puesto que el microorganismo no pude replicarse, la respuesta celular no es muy potente. Infortunadamente, siempre existe el riesgo de obtener, a partir de las cepas vacunales, organismos que recobran su capacidad virulenta y patogénica (revertibles); para algunos virus como el VIH es muy riesgoso usarlos como virus vivos atenuados. ${ }^{11,12}$ Para tratar de evitar esta situación de riesgo se han empleado microorganismos muertos y, de manera más reciente con el advenimiento de la tecnología del ADN recombinante, fue posible el desarrollo de vacunas que usan subunidades antigénicas más que organismos completos. En este tipo de vacunas se han empleado diversos antígenos, como las proteínas recombinantes purificadas, carbohidratos bacterianos, péptidos sintéticos, anticuerpos antiidiotipo, virus y bacterias recombinantes. ${ }^{10-12} \mathrm{~A}$ pesar de que estas vacunas basadas en microorganismos muertos o en subunidades han tenido cierto éxito como vacunas profilácticas, ninguna de estas dos aproximaciones metodológicas es capaz de inducir una respuesta celular adecuada, por lo que nuevas metodologías para desarrollar vacunas con estas cualidades, pero sin el riesgo que implica el uso de patógenos vivos, se hallan todavía en proceso de investigación. ${ }^{12}$

\section{Vacunas de ADN}

Una serie de observaciones al inicio de la década de 1990 demostró que era posible con el ADN desnudo (plásmidos) transfectar células in vivo. ${ }^{13}$ Más adelante se informó que era posible inducir una respuesta humoral contra el antígeno codificado en el plásmido transfectado, ${ }^{14}$ aunque sólo fue hasta el año 1993, cuando se demostró que se podía inducir una respuesta inmunitaria protectora contra un reto letal con el virus de la influenza en ratones inmunizados con $\mathrm{ADN}^{15}$ que se estableció firmemente el concepto de lo que hoy se conoce como vacunas de tercera generación o vacunas de $\mathrm{ADN} .{ }^{16} \mathrm{Con}$ posterioridad, numerosas publicaciones demostraron que diversos antígenos (bacterias, virus, parásitos o 
antígenos de origen tumoral) codificados en plásmidos podían inducir una respuesta inmunitaria protectora en diversos modelos animales. ${ }^{17,18}$

Las vacunas de $\mathrm{ADN}$, también conocidas como vacunas genéticas, vacunas de ácidos nucleicos o vacunas de ADN desnudo, entre otros términos, emplean una metodología relativamente simple que ha abierto una nueva era en la inmunología, con un alto potencial como vacunas profilácticas y terapéuticas. ${ }^{19}$ Todo esto se debe a que combinan muchas de las características deseables de las vacunas tradicionales, pero ofrecen ventajas adicionales, como las siguientes: a) seguridad, dado que no usan microorganismos vivos; b) capacidad de inducir una respuesta inmunitaria celular y humoral; c) facilidad de modificar los antígenos codificados en los plásmidos; d) menor costo cuando se producen a gran escala; ye) vida media mayor, por lo que se consigue una mejor estabilidad en cuanto a la temperatura de almacenamiento y transporte, lo que permite prescindir de la cadena fría utilizada en las vacunas convencionales. ${ }^{20}$

\section{Plásmidos o vectores}

Los vectores son la unidad funcional de las vacunas de ADN. En estos vectores se insertan los genes que codifican a las proteínas de interés y son de origen bacteriano. En la figura 1 se esquematizan los elementos que componen un plásmido típico para su uso como vector en la vacunación con ADN. Los plásmidos bacterianos son moléculas de ADN circular que se autorreplican de forma extracromosómica en las bacterias y se han utilizado de forma amplia para la expresión de proteínas en sistemas de mamíferos. ${ }^{18-21}$ Los genes codificados en estos plásmidos se encuentran bajo el control de promotores, casi siempre de origen viral, como el del citomegalovirus humano (CMV), el virus del sarcoma de Rous (RSV) o el virus de simios 40 (SV-40). Los promotores son secuencias cortas de ADN; a éste se unen diversos factores de transcripción que ayudan a guiar y activar a las polimerasas y se encuentran activos de forma constitutiva en la mayor parte de las células eucariotas; en la actualidad, el promotor empleado con más frecuencia es el CMV ${ }^{10,18}$ Seguido del promotor se encuentra el gen de interés, que a su vez está seguido por una señal de poliadenilación, por ejemplo la región no traducida $3^{\prime}$ del gen de la hormona bovina del crecimiento (BGH-3'-UTR), que contiene las secuencias apropiadas para estabilizar los transcritos del gen de interés. Los plásmidos tienen además diversos genes de resistencia a antibióticos, como son la ampicilina o la kanamicina, lo cual permite su selección en cultivos de bacterias transformadas. ${ }^{21}$ Un elemento importante en los plásmidos es la presencia de motivos $\mathrm{CpG}$ bacte-

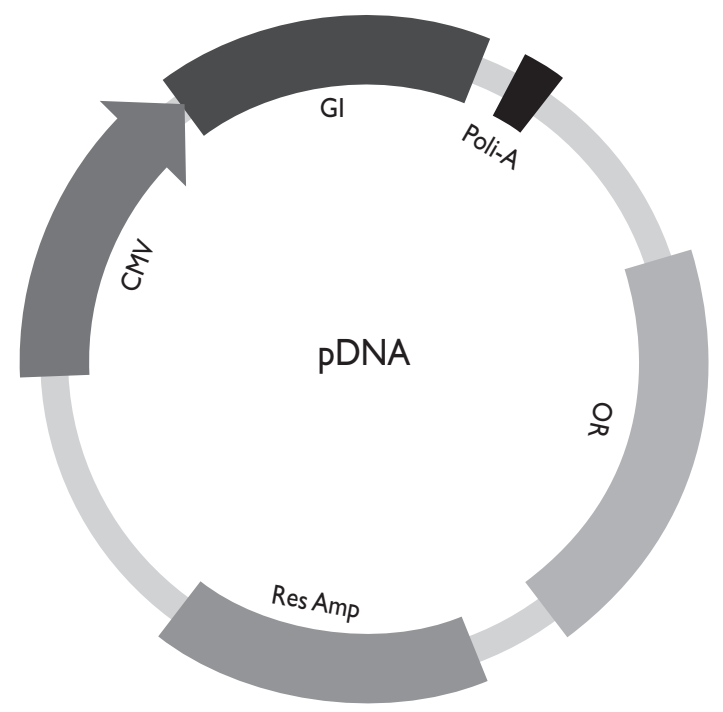

Figura I. Representación esquemática de Un Vector TíPICO DE VACUNAS DE ADN. EL PLÁSMIDO CONTIENE UNA REGIÓN CON EL PROMOTOR (CMV), ADYACENTE AL GEN QUE CODIFICA AL ANTÍGENO DE INTERÉS (GI), SEGUIDO DE LA SEÑAL DE POLIADENILACIÓN. EL VECTOR INCLUYE LAS REGIONES QUE CORRESPONDEN AL GEN DE RESISTENCIA A ANTIBIÓTICOS (RES), EN ESTE EJEMPLO A LA AMPICILINA (AMP) Y AL ORIGEN DE REPLICACIÓN EN BACTERIAS (OR)

rianos, que poseen propiedades inmunomoduladoras y representan un elemento adyuvante intrínseco. ${ }^{19-22}$

\section{Rutas y formas de inoculación}

El sitio de inoculación, así como la forma en que el ADN se libera en el organismo, desempeña una función importante para inducir una respuesta inmunitaria exitosa; se sabe que sólo 1 a 10\% del total del ADN inoculado se procesa de manera adecuada para expresar la proteína de interés. ${ }^{10,21-23}$ Las rutas de inoculación que se han empleado incluyen la piel, el músculo esquelético y las mucosas. La inyección del ADN es el método más usado, ya que no requiere entrenamiento especializado, además del bajo costo, aunque el uso de la pistola génica (gene gun) produce los mejores resultados. ${ }^{22-24} \mathrm{La}$ inoculación de $\mathrm{ADN}$ con la pistola génica se lleva a cabo mediante el acoplamiento del ADN a esferas de oro o tungsteno, que se bombardean en la dermis y capas subdérmicas con la ayuda de helio comprimido, ${ }^{10,20,22,23}$ lo que permite la transfección directa de las células blanco. Esta metodología hace posible usar mucho menos $\mathrm{ADN}$ y es casi 100 veces más eficiente. ${ }^{24} \mathrm{Si}$ se toma en cuenta que 
muchos de los patógenos tienen como vía de entrada las mucosas, ésta es otra vía empleada para inducir una respuesta inmunitaria con las vacunas de $\mathrm{ADN}^{20-23}$

Sin importar cuál sea la forma de inoculación, diversos tipos de células captan el ADN, si bien es necesario que éste lo tomen las células presentadoras de antígeno profesionales (APC, por sus siglas en inglés), ya que son ellas las únicas capaces de activar a las células del sistema inmunitario mediante la presentación de antígenos. ${ }^{10,11}$ Estas células pueden capturar el ADN directamente por la inoculación (transfección) o pueden tomar el antígeno de otras células, como las de músculo esquelético o los queratinocitos, mediante fagocitosis, un mecanismo denominado "presentación cruzada". ${ }^{11,19,22}$

\section{Inducción de la respuesta inmunitaria}

Cuando un plásmido se introduce en la célula se transloca al núcleo, donde se inicia la trascripción del transgén; a continuación, los transcritos se llevan al citoplasma y allí se traducen. Las proteínas recién sintetizadas se degradan en el proteosoma hasta péptidos de 8-10 aminoácidos, que se transportan al retículo endoplásmico, mediante un sistema especializado de transporte que emplea proteínas transportadoras (TAP-I y TAP-II) y una vez en el retículo se vinculan con moléculas de MHC clase I. Los péptidos de gran afinidad con su respectiva molécula de MHC I se estabilizan y entran en la vía secretoria, con lo que alcanzan la superficie celular, donde se acoplan con el receptor de los linfocitos T (TcR) presentes en la superficie de los linfocitos T citotóxicos $\left(\mathrm{CD} 8^{+}\right)$para inducir su activación. ${ }^{14,16,20,22}$

Las proteínas exógenas que se endocitan o fagocitan (presentación cruzada en la inmunización con ADN) entran a la vía endosómica y en ella se degradan en pequeños péptidos de 12 a 25 aminoácidos que luego se vinculan con moléculas del complejo principal de histocompatibilidad (MHC) de clase II y se translocan hacia la superficie de la célula, donde se presentan y unen a los TcR en los linfocitos T cooperadores $\left(\mathrm{CD}^{+}\right)$; todo ello tiene como consecuencia su activación y expansión. ${ }^{14,16,20,22}$

De esta forma, la unión del complejo MHC-péptido y TcR, en las APC y linfocitos T respectivamente, provee la denominada señal 1 de la activación de los linfocitos T. Sin embargo, esta señal 1 es insuficiente para generar una buena respuesta inmunitaria y es necesaria una segunda señal para completar la activación de los linfocitos $\mathrm{CD} 4^{+}$y CD ${ }^{+}{ }^{+10,19,21}$ La señal 2 se induce mediante moléculas coestimuladoras presentes en la superficie de las APC (en su mayor parte células dendríticas [CD]), como las proteínas de la familia B7. Con anterioridad, las $\mathrm{CD}$ requieren una señal para su activación inicial y maduración; esta señal llamada señal 0, o señal de alar$\mathrm{ma}$, la inducen ciertas citocinas inflamatorias, proteínas de choque térmico (HSP) o los motivos $\mathrm{CpG}$ presentes en el ADN bacteriano. El resultado de la señal 0 es la sobreexpresión de moléculas del MHC y coestimuladoras en su superficie, lo que favorece después el proceso de presentación de antígeno (señal 1). En esta etapa, las CD activadas cambian su morfología y perfil de expresión de receptores para quimiocinas, dejan la periferia y migran hacia los ganglios linfáticos donde participan en la activación de linfocitos T y B inmaduros. ${ }^{10,14,20,22}$

Posterior a la etapa de activación se inicia la etapa efectora; los linfocitos $\mathrm{T}$ activados dejan los ganglios linfáticos hacia la periferia y siguen un gradiente de quimiocinas hasta llegar al lugar donde se necesitan y tras la unión de sus TcR con los antígenos expresados en el contexto de MHC apropiado comienzan su etapa efectora mediante la secreción de sustancias toxicas, como las perforinas (células $C D 8^{+}$) o interleucinas con actividad inflamatoria como el INF- $\gamma$ (células CD4 $\left.4^{+}\right) .10,14,21,22$

Por otro lado, los linfocitos B se activan mediante su receptor $(\mathrm{BcR})$ por los antígenos que se sintetizan y secretan o presentan en la superficie de las células que se transfectaron en la inmunización con el ADN. Con posterioridad, los linfocitos $\mathrm{B}$ activados cambian de isotipo; las secuencias que codifican a la región variable de las inmunoglobulinas sufren hipermutación y las clonas con un receptor con mayor afinidad por el antígeno se seleccionan y expanden. Los linfocitos B activados se diferencian al final hacia células de memoria o células plasmáticas; estas últimas pueden: a) continuar la síntesis de anticuerpos o b) establecerse en la medula ósea y continuar también la producción de anticuerpos; por lo tanto, es posible encontrar anticuerpos presentes en el suero y mucosas por largos periodos. ${ }^{10,22}$ La figura 2 esquematiza las posibles rutas para la presentación de antígenos a linfocitos B y T y su activación para realizar su acción efectora.

\section{Optimización de las vacunas de ADN}

A pesar de que las vacunas de ADN han probado ser eficientes en inducir respuestas inmunitarias en modelos murinos, se ha observado que al probarse en primates no humanos, la respuesta inmunitaria es débil, ${ }^{25}$ razón por la cual se han desarrollado diversas estrategias para potenciar la capacidad de este tipo de vacunas. ${ }^{25,26}$ Una de las estrategias para incrementar la eficiencia de las vacunas de $\mathrm{ADN}$ consistió en la coadministración (proteínas recombinantes) o coexpresión (adyuvantes genéticos) de moléculas como las interleucinas. Existe una larga lista de interleucinas que se han utilizado con 


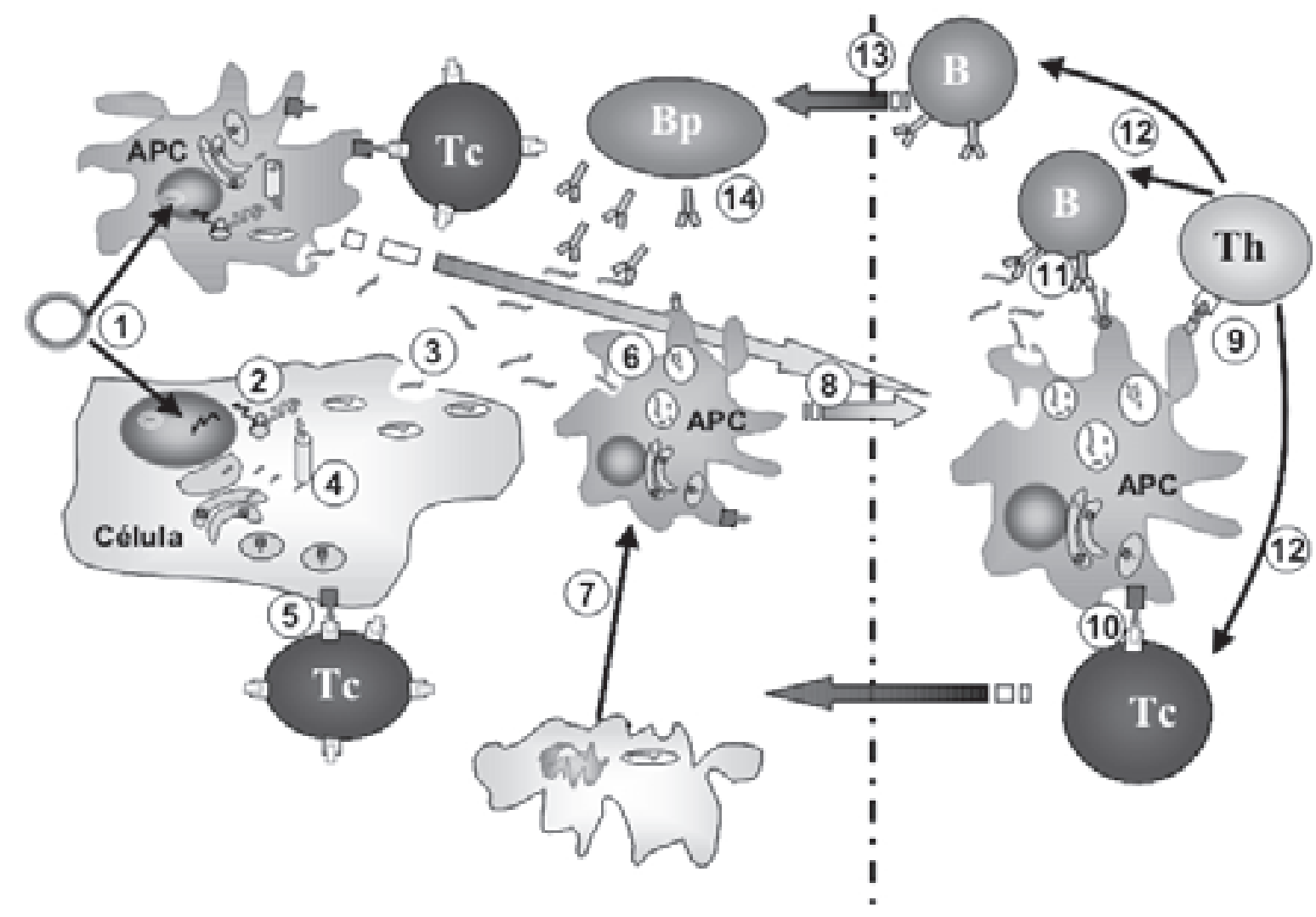

Figura 2. Posibles rutas de presentación de antígenos y activación de linfocitos B yT en la Vacunación con ADN. (I) EL PLÁSMIDO SE INTRODUCE AL ORGANISMO Y LAS CÉlULAS TRANSFECTADAS (UNA CÉLULA SOMÁTICA O UNA CÉLULA PRESENTADORA DE ANTÍGENO PROFESIONAL [APC, POR SUS SIGLAS EN INGLÉS]); ÉSTE SE TRANSLOCA AL NÚCLEO, DONDE SE PRODUCE EL MRNA. (2) El MRNA SE TRADUCE EN LOS RIBOSOMAS Y LA PROTEÍNA SE (3) SECRETA O (4) PROCESA EN EL PROTEOSOMA. LOS PRODUCTOS SE TRANSPORTAN A TRAVÉS DEL RETÍ́CULO ENDOPLÁSMICO Y EL APARATO DE GOLGI, DONDE SE ACOPLAN A MOLÉCULAS DEL COMPLEJO PRINCIPAL DE HISTOCOMPATIBILIDAD CLASE I (MHC I) (5). (6) LASAPC FAGOCITAN A LAS PROTEÍNAS SOLUBLES Y LAS PROCESAN EN LOS ENDOSOMAS, DONDE SE ACOPLAN A MOLÉCULAS DEL COMPLEJO PRINCIPAL DE HISTOCOMPATIBILIDAD CLASE II (MHC II). LAS PROTEÍNAS CODIFICADAS EN LOS PLÁSMIDOS PUEDEN TAMBIÉN CAPTARSE POR LA FAGOCITOCIS DE CÉLULAS TRANSFECTADAS EN ESTADO APOPTÓTICO (7). (8) LAS APC CON LOS ANTÍGENOS ADQUIRIDOS POR LA TRANSFECCIÓN O FAGOCITOSIS MIGRAN HACIA LOS ÓRGANOS LINFOIDES SECUNDARIOS DONDE SE PRESENTAN A LOS LINFOCITOST COOPERADORES (TH) EN EL CONTEXTO DE MHC II (9) O POR "PRESENTACIÓN CRUZADA" en EL CONTEXTO de MHC I A LOS LINFOCITOS T CitotóXICOS (TC) (10). LOS LINFOCITOS B SE ACTIVAN MEDIANTE SU BCR POR LAS PROTEÍNAS PRESENTADAS EN LA SUPERFICIE DE LAS APC O POR LAS PROTEÍNAS LIBERADAS AL MEDIO DEBIDO A APOPTOSIS O LISIS DE LAS APC (I I). LAS LíNEAS PUNTEADAS INDICAN QUE LAS PROTEÍNAS SOLUBLES O CONTENIDAS DENTRO DE LAS CÉlULAS APOPTÓtiCAS (NO APC) PODRÍAN LLEGAR AL BCR DE LOS LINFOCITOS B POR ALGUNA OTRA VÍA NO CONOCIDA. LOS LINFOCITOS TH ACTIVADOS ESTIMULAN A LOS TC Y B (I2), LO CUAL FAVORECE LA SOBREEXPRESIÓN DE MOLÉCULAS DE SUPERFICIE (COESTIMULADORAS), ASÍ COMO TAMBIÉN EL CAMBIO DE ISOTIPO. Los LiNFOCITOS ACTIVAdOS MIGRAN HACIA LA PERIFERIA (13) DONDE LLEVAN A CABO SU ACTIVIDAD EFECTORA (14)

este propósito y de ellas destacan el factor estimulante de granulocitos y los macrófagos (GM-CSF), que ayudan a reclutar células dendríticas y aumentan la respuesta de células T y B. De la misma forma, se han empleado muchas interleucinas de tipo $\mathrm{Th}_{1}$ y $\mathrm{Th}_{2}$, como IL-12,
INF- $\gamma$, IL-15 e IL-18 y IL-4, IL-10 e IL-13, respectivamente. ${ }^{10,25,26}$

Por otro lado, se ha observado que las vacunas de DNA pueden utilizarse en combinación con otro tipo de vacunas, como las basadas en proteínas recombinantes, 
para mejorar la respuesta inmunitaria. Se ha demostrado que cuando se inmuniza con ADN y se utiliza un antígeno específico, y se administra posteriormente un refuerzo con el mismo antígeno pero como proteína recombinante (o virus recombinantes, como la vaccinia), se obtienen respuestas inmunitarias más intensas. ${ }^{10,20,22,26}$

\section{Ensayos en modelos animales y seres humanos}

Los promisorios resultados en los experimentos efectuados en ratones favorecieron el desarrollo de diversos modelos preclínicos de infección para evaluar la eficiencia de las vacunas de ADN. Pueden mencionarse las enfermedades virales como la influenza, las hepatitis B y C, herpes, Ebola y HIV; los patógenos bacterianos Mycobacterium tuberculosis, Mycoplasma pulmonis, Clostridium tetanii, Chlamydia trachomatis y Salmonella typhii; los parásitos como la malaria, la toxoplasmosis, la oncocercosis, la leishmaniasis y la enfermedad de Chagas, entre otros más. ${ }^{10,19,22,27,28}$ Además de las enfermedades infecciosas, las vacunas de ADN se han utilizado como una herramienta para controlar diversos tipos de cáncer, como el de próstata, colorrectal, melanoma, linfoma de células B, etcétera. ${ }^{27,28}$

En general, el uso de las vacunas de ADN en estos modelos preclínicos mostró la inducción de una respuesta inmunitaria baja. No obstante, estos estudios sirvieron para acumular conocimiento en temas importantes como la seguridad y la forma de inoculación. Los esfuerzos más recientes en estudios clínicos enfocados en mejorar la respuesta inmunitaria en seres humanos se basan en el uso de ADN para la inmunización inicial y proteínas o virus recombinantes para suministrar los refuerzos. ${ }^{29,30}$ Esta aproximación metodológica de combinar ADN-proteína ha demostrado que puede estimular la respuesta inmunitaria humoral y celular de mejor forma, en comparación con el uso solo de ADN. ${ }^{28}$ Es posible que la utilización de las vacunas de ADN como una alternativa de las vacunas convencionales tome algún tiempo; empero, el hecho de que un tercio de los estudios clínicos de terapia génica, que se hallan bajo investigación actual, ${ }^{28}$ se base en el empleo de ADN permite prever que ese tiempo puede no ser muy largo.

\section{Conclusiones}

Las vacunas de $\mathrm{ADN}$ representan una estrategia altamente versátil y segura. Aun así, todavía queda mucho por investigar para poder alcanzar en seres humanos el éxito obtenido en modelos animales. El gran potencial de las vacunas de ADN reside en su gran versatilidad, ya que pueden diseñarse plásmidos de acuerdo con el tipo de enfermedad o patógeno contra el cual se quiera inducir una respuesta inmunitaria, y es posible optimizar los antígenos empleados, las rutas de inmunización, el tipo de adyuvantes y los esquemas de inmunización para obtener el tipo de respuesta deseada.

Por último, hay que tomar en cuenta que la aplicación de la tecnología basada en la vacunación con ADN, sobre todo en países en vías de desarrollo, donde tendrían un mayor impacto, puede representar (al igual que cualquier otra tecnología de punta en sus fases iniciales) un alto costo económico. A pesar de lo anterior, las vacunas de $\mathrm{ADN}$ representan una herramienta poderosa y atractiva para el diseño y desarrollo de nuevas estrategias en la lucha contra las enfermedades infecciosas.

\section{Agradecimientos}

El autor agradece a la Dra. Judith González Christen y al Dr. Fernando R. Esquivel por sus comentarios y revisión del manuscrito.

\section{Referencias}

I. CDC.Achievements in Public Health, 1900-1999. MMWR Morb Mortal Wkly Rep 1999;48:243-248.

2. Kurstak E.Abstracts of the Third World Congress on Vaccines and Immunisation, WCVI 2002. Infections Control World Organization (ICWO) 2002;4-9:92.

3. Morens DM, Folkers GK, Fauci AS. The challenge of emerging and reemerging infectious diseases. Nature 2004;430:242-249.

4. World Health Organization. The World Health Report 2004. Geneve: World Health Organization, 2004.

5. Kurstak E. Towards the new global vaccinology era in prevention and control of diseases. Vaccine 2003;21:580-581.

6.Wilson CB, Marcuse EK.Vaccine safety--vaccine benefits: science and the public's perception. Nat Rev Immunol 200 I; I:160-165.

7. Edwards KM, Decker MD. Combination vaccines: hopes and challenges. Pediatr Infect Dis J 1994; 13:345-347.

8. Zepp F, Knuf M, Heininger U, Jahn K, Collard A, Habermehl P, et al. Safety, reactogenicity and immunogenicity of a combined hexavalent tetanus, diphtheria, acellular pertussis, hepatitis B, inactivated poliovirus vaccine and Haemophilus influenzae type $b$ conjugate vaccine, for primary immunization of infants. Vaccine 2004;22:2226-2233

9. Zinka B, Rauch E, Buettner A, Rueff F, Penning R. Unexplained cases of sudden infant death shortly after hexavalent vaccination. Vaccine 2006;24:5779-5780.

10. Reyes-Sandoval A, Ertl HC. DNA vaccines. Curr Mol Med 200 I; : 217-243.

I I. Shroff KE, Smith LR, Baine Y, Higgins TJ. Potential for plasmid DNAs as vaccines for the new millennium. Pharm Sci Technol Today 1999;2:205-2I2. 12. Giese M. DNA-antiviral vaccines: new developments and approaches: a review.Virus Genes 1998;17:219-232.

13. Wolff JA, Malone RW,Williams P, Chong W, Acsadi G, Jani A, et al. Direct gene transfer into mouse muscle in vivo. Science 1990;247: I 465- I 468. 14. Tang DC, DeVit M, Johnson SA. Genetic immunization is a simple method for eliciting an immune response. Nature 1992;356:152-154. 
15. Ulmer JB, Donnelly J], Parker SE, Rhodes GH, Felgner PL, Dwarki $\mathrm{VJ}$, et al. Heterologous protection against influenza by injection of DNA encoding a viral protein. Science 1993;259: 1745-1749.

16.Waine G], McManus DP. Nucleic acids: vaccines of the future. Parasitol Today 1995; II: I I3-I I6.

17. Lewis PJ, Babiuk LA. DNA vaccines: a review.Adv Res 1999;94:I29-I88. 18. Babiuk LA, Babiuk SL, Loehr B, van Drunen Littel-van den Hurk S. Nucleic acid vaccines: research tools or commercial reality.Vet Immunol Immunopathol 2000;76:I-23.

19. Srivastava IK, Liu MA. Gene vaccines. Ann Intern Med 2003; 138:550-559. 20. Shedlock DJ,Weiner DB. DNA vaccination: antigen presentation and the induction of immunity.J Leukoc Biol 2000;68:793-806.

21. Kowalczyk DW, Ertl HC. Immune responses to DNA vaccines. Cell Mol Life Sci 1999;55:751-770.

22. Huygen K. Plasmid DNA vaccination. Microbes Infect 2005;7:932-938

23. Watts AM, Kennedy RC. DNA vaccination strategies against infectious diseases. Int J Parasitol 1999;29: I |49-I I 63.

24. Babiuk LA, Pontarollo R, Babiuk S, Loehr B, van Drunen Littel-van den Hurk $S$. Induction of immune responses by DNA vaccines in large animals. Vaccine 2003;21:649-658
25. Scheerlinck JY. Genetic adjuvants for DNA vaccines.Vaccine 200I;19:2647-2656.

26. Berzofsky JA,Ahlers JD, Belyakov IM. Strategies for designing and optimizing new generation vaccines. Nat Rev Immunol 200I;I:209-2 I9. 27. Rice J, Ottensmeier $\mathrm{CH}$, Stevenson FK. DNA vaccines: precision tools for activating effective immunity against cancer. Nat Rev Cancer 2008;8: 108-120.

28. Kutzler MA, Weiner DB. DNA vaccines: ready for prime time? Nat Rev Genet 2008;9:776-788.

29. Peters BS, Jaoko W, Vardas E, Panayotakopoulos G, Fast P, Schmidt C, et al. Studies of a prophylactic HIV-I vaccine candidate based on modified vaccinia virus Ankara (MVA) with and without DNA priming: effects of dosage and route on safety and immunogenicity. Vaccine 2007;25:2120-2I 27. 30. Dorrell L, Williams P, Suttill A, Brown D, Roberts J, Conlon C, et al. Safety and tolerability of recombinant modified vaccinia virus Ankara expressing an HIV-I gag/multiepitope immunogen (MVA.HIVA) in IV-Iinfected persons receiving combination antiretroviral therapy.Vaccine 2007;25:3277-3283. 